\title{
A novel diffuse gastric cancer susceptibility variant in E-cadherin (CDHI) intron 2: A case control study in an Italian population Soroush Nasri ${ }^{1}$, Helen More ${ }^{1}$, Francesco Graziano ${ }^{2}$, Annamaria Ruzzo ${ }^{3}$, Emily Wilson ${ }^{4}$, Anita Dunbier ${ }^{5}$, Cushla McKinney6, Tony Merriman ${ }^{6}$, Parry Guilford ${ }^{1}$, Mauro Magnani ${ }^{3}$ and Bostjan Humar*1
}

\begin{abstract}
Address: ${ }^{1}$ Cancer Genetics Laboratory, Department of Biochemistry, University of Otago, Dunedin 9054, Aotearoa New Zealand, ${ }^{2}$ Medical Oncology Unit, Azienda Ospedale "S. Salvatore", 61100 Pesaro, Italy, ${ }^{3}$ Institute of Biochemistry, University of Urbino, 61029 Urbino, Italy, ${ }^{4}$ Department of Molecular Medicine \& Pathology, University of Auckland, Auckland 1142, Aotearoa, New Zealand, ${ }^{5}$ Institute of Cancer Research, London SW3 6JB, UK and ' Department of Biochemistry, University of Otago, Dunedin 9054, Aotearoa, New Zealand

Email: Soroush Nasri - nasso300@student.otago.ac.nz; Helen More - helen.more@otago.ac.nz; Francesco Graziano - frada@tin.it; Annamaria Ruzzo - Annamaria.ruzzo@uniurb.it; Emily Wilson - emily.wilson@auckland.ac.nz; Anita Dunbier - Anita.Dunbier@icr.ac.uk; Cushla McKinney - cushla.mckinney@stonebow.otago.ac.nz; Tony Merriman - tony.merriman@otago.ac.nz;

Parry Guilford - parry.guilford@otago.ac.nz; Mauro Magnani - Mauro.magnani@uniurb.it; Bostjan Humar* - bostjan.humar@otago.ac.nz

* Corresponding author
\end{abstract}

Published: 15 May 2008

BMC Cancer 2008, 8:138 doi:10.1186/147|-2407-8-138

This article is available from: http://www.biomedcentral.com/147/-2407/8/138

(C) 2008 Nasri et al; licensee BioMed Central Ltd.

This is an Open Access article distributed under the terms of the Creative Commons Attribution License (http://creativecommons.org/licenses/by/2.0), which permits unrestricted use, distribution, and reproduction in any medium, provided the original work is properly cited.
Received: 29 November 2007

Accepted: 15 May 2008

\begin{abstract}
Background: Inherited genetic factors such as E-cadherin $(C D H I)$ promoter variants are believed to influence the risk towards sporadic diffuse gastric cancer (DGC). Recently, a new regulatory region essential for $C D H I$ transcription has been identified in $C D H I$ intron 2.

Methods: We genotyped all known polymorphisms located within conserved sequences of CDHI intron 2 (rs10673765, rs9932686, rsII25557, rs9282650, rs9931853) in an Italian population consisting of 134 DGC cases and 100 healthy controls (55 patient relatives and 45 unrelated, matched individuals). The influence of individual variants on DGC risk was assessed using $\chi^{2}$-tests and logistic regression. The relative contribution of alleles was estimated by haplotype analysis.

Results: We observed a significant $(p<0.0004)$ association of the $C D H I \quad 163+37235 \mathrm{G}>\mathrm{A}$ variant (rs I I 25557) with DGC risk. Odds ratios were $4.55(95 \% \mathrm{Cl}=2.09-9.93)$ and $\mathrm{I} .38(95 \% \mathrm{Cl}=0.75-$ 2.55) for AA and GA carriers, respectively. When adjusted for age, sex, smoking status, alcohol intake and $H$. pylori infection, the risk estimates remained largely significant for AA carriers. Haplotype analysis suggested the $163+37235 A$-allele contributes to disease risk independently of the other variants studied.
\end{abstract}

Conclusion: The CDHI 163+37235G>A polymorphism may represent a novel susceptibility variant for sporadic DGC if confirmed in other populations. Considering the broad expression of E-cadherin in epithelia, this exploratory study encourages further evaluation of the $163+37235 \mathrm{~A}$ allele as a susceptibility variant in other carcinomas. 


\section{Background}

Gastric cancer is a major cause of cancer-related mortality and is usually classified into two histological types, the intestinal and the diffuse form (Lauren classification [1]). The general incidence rates for stomach cancer are in a steady decline, largely due to decreasing rates of the intestinal cancer-type. This falling frequency is believed to be the result of improved nutrition and sanitary conditions. In contrast, the incidence of diffuse gastric cancer (DGC) alone appears more stable over the past few decades $[1,2]$. Such a constant rate suggests a larger contribution of inherited genetic risk rather than environmental factors to the diffuse form of stomach cancer.

Owing to its early development underneath the gastric mucosal surface [3], DGC is usually diagnosed at an advanced stage and consequently associated with a poorer outcome [1]. Therefore, genetic DGC markers may facilitate the identification of individuals at risk and thereby contribute to an improvement in DGC diagnosis and therapy.

On a molecular level, DGC is distinguished from the intestinal type on the basis of its abnormal expression of the cell-cell adhesion molecule E-cadherin [4]. E-cadherin is the key component of the epithelial adherens junction and as such is required for functional intercellular adhesion within epithelial sheets [5]. In contrast to many other epithelial cancers, E-cadherin is downregulated very early during DGC development, suggesting a role in the initiation of this disease [3]. Mutation and promoter hypermethylation of the E-cadherin gene $(\mathrm{CDH} 1)$ are the most consistent genetic alterations observed in sporadic DGC $[6,7]$. Furthermore, $C D H 1$ germline mutations predispose to hereditary DGC [8] consistent with an initiating function of E-cadherin deficiency in DGC. CDH1 germline mutations usually co-segregate with a dominant pattern of disease among affected families, and occasionally can be found in isolated DGC cases diagnosed at a young age (<45 y) [9]. However, they account for only about $1 \%$ of all DGC cases [9] and hence cannot explain the genetic aetiology postulated to contribute to apparent sporadic DGC cases. Genetic alterations other than CDH1 germline mutations are therefore likely to add to the risk of developing DGC in the absence of a clear family history or a young age at diagnosis.

Common allelic variants with a mild functional effect can influence the risk for sporadic disease. Indeed, a single nucleotide polymorphism (SNP) within the CDH1 promoter $(-160 \mathrm{C}>\mathrm{A})$ has been associated with a significantly increased risk of sporadic DGC in certain high-incidence populations [10-13]. Of the studied CDH1 SNPs, the $160 \mathrm{~A}$ promoter allele is so far the only variant implicated in DGC risk but appears to act in combination with other CDH1 polymorphisms [10,13].
Recently, a new CDH1 regulatory region has been described [14]. This region is contained within CDH1 intron 2, the largest non-coding $C D H 1$ segment (66\% of the total sequence) and has been shown to be required for both the initiation and maintenance of transcriptional CDH1 activity in differentiated epithelia. Importantly, intron 2 sequences are also necessary for normal CDH1 transcription during adult life, providing the possibility that variants within this region may affect diffuse gastric carcinogenesis.

In this study, we genotyped all known variants located within the conserved sequences of CDH1 intron 2 and determined their allelic frequencies in groups of Italian sporadic DGC cases and healthy individuals to unravel possible associations with disease.

\section{Methods \\ Patients}

DNA samples were obtained from 134 DGC patients who were natives of the District of Pesaro-Urbino, Region Marche, Central Italy. After surgery, the DGC diagnosis was independently confirmed by two pathologists. Patients were clinically evaluated at the local Medical Oncology Unit (Hospital d'Urbino), where they also completed a demographic sheet including their personal and familial cancer history. Data were verified during interviews with their oncology physicians and their family history was traced back for $\geq 3$ generations and laterally to $2^{\text {nd }}$ and $3^{\text {rd }}$ degree relatives. On the basis of this evaluation, none of the patients met the clinical criteria for known familial cancer syndromes. The inclusion criteria for eligible patients were: Caucasian ethnicity, native of the studied geographical area and lack of family history of cancer. The same criteria plus lack of personal history of cancer were adopted for controls. Control DNA samples were obtained from 55 healthy relatives, who were either unaffected parents $(n=15)$, siblings (22) or children (18) of the studied DGC patients. As healthy relatives were not available for every DGC patient, DNA samples from a group of unrelated healthy individuals $(n=45)$ identified through the pool of former and current blood donors from the Hospital d'Urbino were included yielding a total of 100 controls. Unrelated controls were randomly selected with frequencies matching to cases by age and sex. The mean age of DGC patients without relatives was $54.6 \mathrm{y} \pm 11.41 \mathrm{SD}$, while that of their matched controls was $52.2 \mathrm{y} \pm 10.21 \mathrm{SD}$. All subjects were interviewed about their smoking and drinking habits. H. pylori status was determined by pathological examination of gastric samples for cases, and by blood or breath tests for controls. The ethical requirements were verified and approved by the internal Ethical Committee (Hospital d'Urbino) and all study participants gave their written informed consent. 


\section{CDHI intron 2 conserved regions and polymorphisms}

Conserved regions of CDH1 intron 2 (GenBank NC 000016) were identified by retrieving corresponding human, chimpanzee, rat and mouse sequences from the NCBI database (NCBI, Entrez nucleotide) followed by alignment using the NCBI server (NCBI, Basic Local Alignment Search Tool) and Invitrogen Vector NTI Advance ${ }^{\mathrm{TM}}$ 9.0 software (Accelrys Software Inc, San Diego, USA). Conserved regions were defined as having less than 5\% sequence variations among the different species. The conserved regions were PCR-amplified into overlapping fragments of about 200 bp size. The corresponding primers (see Table 1 for sequences and conditions) were designed using the GeneFisher online tool [15] and manufactured by Sigma-Proligo (Sigma-Aldrich Corporation, St. Louis, USA). FastStart Taq DNA Polymerase (Roche, Basel, Switzerland) and PTC-200 PCR machines (MJ Research, Waltham, USA) were used. The following polymorphisms are located (Ensemble GenomeBrowser [16]) within the amplified regions: 163+14184 4 AGGG (rs10673765, located in PCR fragment C2F1), 163+14384C>T (rs9932686, C2F2), 163+37235G>A (rs1125557, C3F2), $163+37276 \mathrm{~T}>\mathrm{A}(\mathrm{rs} 9282650, \mathrm{C} 3 \mathrm{~F} 2)$, and $163+49526 \mathrm{C}>\mathrm{G}$ (rs9931853, C4F1). The TESS online tool [17] was used to search for putative transcription binding factor sites that may be affected by the above variants.

\section{Single-strand conformation polymorphism}

Single-strand conformation polymorphism (SSCP) was used to scan the conserved intron 2 region in 19 Italian DGC patients for the presence of additional common but population-specific polymorphisms. SSCP was performed as described [18], with the exception that ULS ${ }^{\mathrm{TM}} 495$ fluorophore (Kreatech Biotechnology, Amsterdam, Netherlands) was used instead of radioactivity to label the fragments. In brief, $1 \mu$ l PCR product was incubated with $0.2 \mu$ ldye in a $20 \mu \mathrm{l}$ reaction. Gels were scanned using an FX molecular imager (BioRad, Hercules, USA) at $488 \mathrm{~nm}$.

\section{Genotyping}

The following restriction enzymes were used for the genotyping of DNA variants: $0.06 \mathrm{U} / \mu \mathrm{l}$ BsaXI for $163+14184 \Delta$ AGGG, $1 \mathrm{U} / \mu \mathrm{l}$ BanII for $163+14384 \mathrm{C}>\mathrm{T}, 0.2$ $\mathrm{U} / \mu \mathrm{l}$ MaeIII for $163+37276 \mathrm{~T}>\mathrm{A}$, and $0.4 \mathrm{U} / \mu \mathrm{l} H$ paII for $163+49526 \mathrm{C}>\mathrm{G}$. All enzymes were from New England Biolabs (Ipswich, USA) with the exception of MaeIII from Roche (Basel, Switzerland). Reactions were incubated overnight and fragments were separated on $4 \%(\mathrm{w} / \mathrm{v})$ agarose gels.

Polymorphisms $163+37235 \mathrm{G}>\mathrm{A}$ and $163+37276 \mathrm{~T}>\mathrm{A}$ were genotyped on a ABI Prism 7900 (Applied Biosystems, Foster City, USA) using the real-time PCR-based allelic discrimination assays from Applied Biosystems according to the instructions provided.

\section{Sequencing}

Detected variants were verified by direct sequencing using the USB thermosequencing kit (USB, Cleveland, USA) and a LiCor 4000L DNA sequencer (LiCor, Lincoln, Nebraska USA).

Table I: PCR primers and conditions

\begin{tabular}{|c|c|c|c|c|c|}
\hline & Forward primer & Reverse primer & $\mathbf{T}_{\mathbf{a}} *$ & $\mathbf{M g}^{++\dagger}$ & DMSO $\ddagger$ \\
\hline CIFI & ccgccttaaagaaactcttg & accggtggcaaatactag & $65^{\circ} \mathrm{C}$ & 1.5 & - \\
\hline CIF2 & tagaagggttgaacctgttc & tcttagtccacgagaagaag & $65^{\circ} \mathrm{C}$ & 1.5 & - \\
\hline CIF3 & taggagagcttgtaacaagc & cactcggttctaccgaag & $65^{\circ} \mathrm{C}$ & 1.5 & - \\
\hline C2F I & tgtattagccacagagaag & ctaaaactagaccacgaag & $65^{\circ} \mathrm{C}$ & 1.5 & - \\
\hline C2F2 & gtcacaaaacagcttg & ccttccttgagcaaggc & $65^{\circ} \mathrm{C}$ & 1.5 & - \\
\hline C3FI & ttgcctaaggccccctttttgttc & gaatctgcgaagtctacatc & $65^{\circ} \mathrm{C}$ & 1.5 & - \\
\hline C3F2 & acactagccacacatgggactcaag & tgctggtgtggattcaaatgtg & $65^{\circ} \mathrm{C}$ & 1.5 & - \\
\hline C4F I & acctccgcctcctgggttcaagc & ttcctccogcttagtg & $60^{\circ} \mathrm{C}$ & 1.5 & - \\
\hline C4F2 & tggccaggcctgtcttaaactc & ttcttaggtccgtgggtttttacg & $65^{\circ} \mathrm{C}$ & 1.5 & - \\
\hline C4F3 & aaagtgctgggattacaggtgtgag & tcgataatcccgagaactc & $55^{\circ} \mathrm{C}$ & 1.0 & + \\
\hline C4F4 & gaaccataggactttgactgatgg & actgatggttatccgggttcccttg & $65^{\circ} \mathrm{C}$ & 1.5 & - \\
\hline C4F5 & agctgttgagctgtcatcacaatcc & gaatttcctacccgtctatggtagg & $65^{\circ} \mathrm{C}$ & 1.5 & - \\
\hline C5FI & tagtggggagtggggtcttagcttc & tcgttcaccctcctttcttcttacc & $58^{\circ} \mathrm{C}$ & 1.5 & - \\
\hline C5F2 & gggcatgttgaaatatacccagtc & tctgagtaatagaggggtacgttgg & $65^{\circ} \mathrm{C}$ & 1.5 & - \\
\hline C5F3 & cttgccagcgtgacagtg & cgaaaccccgtggagtag & $65^{\circ} \mathrm{C}$ & 1.5 & - \\
\hline C5F4 & caggttggggctcctcgtcatactg & cttccgacgtgacttaaggaaagag & $65^{\circ} \mathrm{C}$ & 1.5 & - \\
\hline C5F5 & gcttgtctcaactttcactgtc & gaatttcctacccgtctatggtagg & $65^{\circ} \mathrm{C}$ & 1.5 & - \\
\hline C6F I & tggtattcaggaggatgcag & acctacgatcgtaaaaagt & $65^{\circ} \mathrm{C}$ & 1.5 & - \\
\hline C6F2 & cccatcaatgcttatttgttctt & gcctgggagacggagact & $65^{\circ} \mathrm{C}$ & 1.5 & - \\
\hline C6F3 & tgggctgtttgagttttgttc & cggtgtaaaaggttcgtgac & $65^{\circ} \mathrm{C}$ & 1.5 & - \\
\hline
\end{tabular}

$* \mathrm{~T}_{\mathrm{a}}$ annealing temperature; $\uparrow \mathrm{Mg}^{++}$-concentration is given in $\mathrm{mM}$; $\neq$ DMSO was added at $5 \%$ f.c. 


\section{Statistical analysis}

Differential distributions among cases and controls were assessed by the $\chi^{2}$-test (with $\mathrm{df}=2$ for genotypes and $\mathrm{df}=$ 1 for alleles). Risk was estimated by univariate analysis and by multiple logistic regression (STATA software, StataCorp LP, College Station, USA). The $\chi^{2}$-test $(\mathrm{df}=2)$ was also used to examine deviations from Hardy-Weinberg equilibrium. Age differences among patients carrying different genotypes were calculated using a 2-tailed t-test.

Haplotype frequencies were reconstructed from unphased genotypes and linkage disequilibrium (LD) between SNPs was estimated using the SHEsis software platform $[19,20]$. Only haplotypes with a relative frequency $>0.03$ in either cases or controls were included in the analysis. Global association of haplotypes with disease was calculated by a $\chi^{2}$-test ( $\mathrm{df}=7$ ). The $163+14184 \Delta$ AGGG and $163+14384 \mathrm{C}>\mathrm{T}$ variants were not included into the final analysis as they were not informative. The association of individual haplotypes with disease was based on $2 \times 2$ contingency tables in comparison to the A-A-C haplotype. $\mathrm{LD}$ was expressed as $\mathrm{r}^{2}$, with $\mathrm{r}^{2}=1$ indicating complete $\mathrm{LD}$, $\mathrm{r}^{2}=0$ absence of $\mathrm{LD}$, and $\mathrm{r}^{2}<0.33$ suggesting minimal $\mathrm{LD}$.

\section{Results}

Six conserved regions with a total size of $3.2 \mathrm{kbp}$ were identified within $C D H 1$ intron 2. Apart from the five known polymorphisms (CDH1163+14184AAGGG (rs10673765), 163+14384C $>\mathrm{T} \quad$ (rs9932686), $163+37235 \mathrm{G}>\mathrm{A} \quad(\mathrm{rs} 1125557), \quad 163+37276 \mathrm{~T}>\mathrm{A}$ (rs9282650), and 163+49526C>G (rs9931853)), no additional common polymorphisms specific for the Italian population under study were discovered by SSCP in the six regions.

Using restriction fragment length polymorphism and allelic discrimination assays, the relative frequencies of the genotypes resulting from the five variants were determined in the DGC cases and the controls. Sequencing of random samples confirmed the respective genotypes. All polymorphisms were in Hardy-Weinberg equilibrium for both cases and controls ( $p>0.19)$. Table 2 summarises the genotype distributions and their differences between cases and controls.

Of the investigated variants, only the $163+37235 \mathrm{G}>\mathrm{A}$ SNP was significantly associated with disease due to an

Table 2: $C D H I$ intron 2 genotype distributions among DGC cases and controls

\begin{tabular}{|c|c|c|c|c|c|c|c|c|}
\hline \multicolumn{3}{|c|}{$+|4| 84 \Delta$ AGGG cases $(n=134)$} & \multicolumn{3}{|c|}{$+|4| 84 \Delta$ AGGG controls $(n=100)$} & \multirow{2}{*}{$\frac{\chi^{2} \text {-test }}{p}$} & \multirow{2}{*}{$\begin{array}{c}\text { OR }(95 \% \mathrm{Cl})^{*}, \dagger \\
\Delta / \Delta \mathrm{vs}+/+\end{array}$} & \multirow{2}{*}{$\begin{array}{c}\text { OR }(95 \% \mathrm{Cl})^{*}, \dagger \\
+/ \Delta \mathrm{vs}+/+\end{array}$} \\
\hline$+/+$ & $+/ \Delta$ & $\Delta / \Delta$ & $+/+$ & $+/ \Delta$ & $\Delta / \Delta$ & & & \\
\hline 128 & 4 & 2 & 96 & 3 & $\mathrm{I}$ & 0.947 & $1.50(0.13-16.78)$ & $1.00(0.21-4.57)$ \\
\hline $95.5 \%$ & $3 \%$ & $1.5 \%$ & $97 \%$ & $1.5 \%$ & $1.5 \%$ & & $14.2 \%$ & $2.5 \%$ \\
\hline \multicolumn{3}{|c|}{$+\mid 4384 C>T$ cases $(n=\mid 34)$} & \multicolumn{3}{|c|}{$+\mid 4384 C>T$ controls $(n=100)$} & $\chi^{2}$-test & OR (95\%CI) & OR (95\%Cl) \\
\hline CC & CT & TT & CC & CT & TT & $\mathbf{p}$ & TT vs CC & CT vs CC \\
\hline 130 & 2 & 2 & 98 & 1 & 1 & 0.895 & $1.51(0.13-16.87)$ & $1.51(0.13-16.87)$ \\
\hline $97.0 \%$ & $1.5 \%$ & $1.5 \%$ & $98.0 \%$ & $1.0 \%$ & $1.0 \%$ & & $12.3 \%$ & $12.3 \%$ \\
\hline \multicolumn{3}{|c|}{$+37235 G>A$ cases $(n=134)$} & \multicolumn{3}{|c|}{$+37235 G>A$ controls $(n=100)$} & $\chi^{2}$-test & OR (95\%CI) & OR (95\%Cl) \\
\hline GG & GA & AA & GG & GA & AA & $\mathbf{p}$ & AA vs GG & GA vs GG \\
\hline 30 & 56 & 48 & 37 & 50 & 13 & 0.0003 & $4.55(2.09-9.93)$ & $1.38(0.75-2.55)$ \\
\hline $22.4 \%$ & $41.8 \%$ & $35.8 \%$ & $37.0 \%$ & $50.0 \%$ & $13.0 \%$ & & $100 \%$ & $40.6 \%$ \\
\hline \multicolumn{3}{|c|}{$+37276 T>A$ cases $(n=134)$} & \multicolumn{3}{|c|}{$+37276 T>A$ controls $(n=100)$} & $\chi^{2}$-test & OR (95\%CI) & OR (95\%Cl) \\
\hline TT & TA & AA & TT & TA & AA & $\mathbf{p}$ & AA vs TT & TA vs TT \\
\hline 65 & 65 & 4 & 46 & 51 & 3 & 0.929 & $0.94(0.20-4.42)$ & $0.90(0.53-1.53)$ \\
\hline $48.5 \%$ & $48.5 \%$ & $3.0 \%$ & $46.0 \%$ & $51.0 \%$ & $3.0 \%$ & & $1.9 \%$ & $1.6 \%$ \\
\hline \multicolumn{3}{|c|}{$49526 C>G$ cases $(n=134)$} & \multicolumn{3}{|c|}{$+49526 C>G$ controls $(n=100)$} & $\chi^{2}$-test & OR $(95 \% \mathrm{CI})$ & OR (95\%Cl) \\
\hline CC & CG & GG & CC & CG & GG & $\mathbf{p}$ & GG vs CC & CG vs GG \\
\hline 34 & 82 & 18 & 30 & 58 & 12 & 0.727 & $1.32(0.55-3.19)$ & $1.25(0.69-2.26)$ \\
\hline $25.4 \%$ & $61.2 \%$ & $13.4 \%$ & $30.0 \%$ & $58.0 \%$ & $12.0 \%$ & & $32.2 \%$ & $22.5 \%$ \\
\hline
\end{tabular}

*OR values are unadjusted.

tThe percentage below the OR values estimates the power of association for each variant at the corresponding OR level and assuming a significance level of $5 \%$. 
overrepresentation of the A-allele among the DGC cases (56.7\% vs. $38 \%$ in controls, $\chi^{2}=16.1, \mathrm{p}<0.0001$; see Table 2). The 163+37235AA genotype was 2.8 times more frequent in cases compared to controls. The corresponding Odds Ratio (OR) suggested a significantly elevated risk of developing DGC for AA carriers relative to GG carriers $(\mathrm{OR}=4.55,95 \% \mathrm{CI}=2.09-9.93, \mathrm{p}=0.0002$, power of association 100\%; Table 2). No significant increase in risk was apparent from carrying the GA-genotype $(\mathrm{OR}=$ $1.38,95 \% \mathrm{CI}=0.75-2.55, \mathrm{p}=0.3$, power of association 41\%; Table 2). The DGC risk for AA carriers remained significant, when ORs were adjusted for age, sex, alcohol intake and H. pylori infection (Table 3). In smokers, however, the associated risk was only of borderline significance ( $\mathrm{p}=0.089$, Table 3 ). The risks associated with the other variants studied remained non-significant following adjustment (data not shown). No association was observed between the $163+37235 \mathrm{G}>\mathrm{A}$ SNP and age at diagnosis $(\mathrm{p}>0.16)$.

To determine whether the CDH1 163+37235A-allele confers DGC risk independently or in combination with the other intron 2 variants, haplotypes resulting from the five polymorphisms were reconstructed and their frequencies were estimated in the cases and controls. The two 5'-variants were not informative and were thus excluded. The intron 2 haplotypes showed a global association with disease $\left(\mathrm{df}=7, \chi^{2}=24.09, \mathrm{p}<0.002\right)$. In general, haplotypes containing the $163+37235 \mathrm{~A}$-allele were more frequent in cases compared to controls, while three of the four haplotypes with the G-allele were more frequent among the controls (Table 4). The strongest association with disease was observed for the AAG and the ATC haplotypes (with $163+37235 A$ at position 1). Conversely, the GAG and the GTC haplotypes showed the strongest protection. Linkage

Table 3: Adjusted ORs associated with the $C D H I$ intron $2163+37235 G>A$ variant

\begin{tabular}{|c|c|c|c|c|c|c|c|}
\hline & \multirow[t]{2}{*}{ Variable } & \multirow[t]{2}{*}{$163+37235$} & \multicolumn{2}{|c|}{ Cases } & \multicolumn{2}{|c|}{ Controls } & \multirow[t]{2}{*}{ OR (95\% CI) } \\
\hline & & & $\mathbf{n}$ & $\%$ & $\mathbf{n}$ & $\%$ & \\
\hline \multirow[t]{6}{*}{ Age } & $\leq$ Median & GG & 17 & 20 & 20 & 34 & 1 \\
\hline & & GA & 37 & 45 & 30 & 52 & $1.45(0.65-3.25)$ \\
\hline & & AA & 29 & 35 & 8 & 14 & 4.26 (1.55-1 I.77) \\
\hline & $>$ Median & GG & 13 & 25 & 17 & 40 & I \\
\hline & & GA & 19 & 37 & 20 & 48 & $1.24(0.48-3.24)$ \\
\hline & & $\mathbf{A A}$ & 19 & 37 & 5 & 12 & $4.97(1.47-16.86)$ \\
\hline \multirow[t]{6}{*}{ Sex } & Female & GG & 13 & 20 & 20 & 34 & I \\
\hline & & GA & 28 & 44 & 30 & 51 & $1.44(0.60-3.42)$ \\
\hline & & $\mathbf{A A}$ & 23 & 36 & 9 & 15 & $3.93(1.39-11.12)$ \\
\hline & Male & GG & 17 & 24 & 17 & 41 & I \\
\hline & & GA & 28 & 40 & 20 & 49 & $1.40(0.58-3.39)$ \\
\hline & & $\mathbf{A A}$ & 25 & 36 & 4 & 10 & $6.25(1.79-21.84)$ \\
\hline \multirow[t]{6}{*}{ Smoking } & Never & GG & 17 & 24 & 25 & 42 & I \\
\hline & & GA & 30 & 42 & 30 & 50 & $1.47(0.66-3.26)$ \\
\hline & & $\mathbf{A A}$ & 25 & 35 & 5 & 8 & 7.35 (2.34-23.0I) \\
\hline & Ever & GG & 13 & 21 & 12 & 30 & 1 \\
\hline & & GA & 26 & 42 & 20 & 50 & $1.20(0.45-3.19)$ \\
\hline & & $\mathbf{A A}$ & 23 & 37 & 8 & 20 & $2.65(0.86-8.16))$ \\
\hline \multirow[t]{6}{*}{ Alcohol } & $\leq 20$ g/day & GG & 24 & 26 & 26 & 40 & I \\
\hline & & GA & 35 & 38 & 31 & 48 & $1.22(0.59-2.55)$ \\
\hline & & AA & 34 & 37 & 8 & 12 & $4.60(1.78-11.90)$ \\
\hline & $>20$ g/day & GG & 6 & 15 & II & 31 & I \\
\hline & & GA & 21 & 51 & 19 & 54 & $2.01(0.63-6.55)$ \\
\hline & & $\mathbf{A A}$ & 14 & 34 & 5 & 15 & $5.13(1.23-21.36)$ \\
\hline \multirow[t]{6}{*}{ H. pylori } & Negative & GG & 2 & II & 16 & 37 & 1 \\
\hline & & GA & 22 & 48 & 22 & 51 & $3.2(1.00-10.26)$ \\
\hline & & $\mathbf{A A}$ & 19 & 41 & 5 & 12 & $12.16(2.98-49.64)$ \\
\hline & Positive & GG & 25 & 28 & 21 & 37 & I \\
\hline & & GA & 34 & 39 & 28 & 49 & $1.02(0.472--.19)$ \\
\hline & & AA & 29 & 33 & 8 & 14 & 3.045 (1.15-8.07) \\
\hline
\end{tabular}


Table 4: $C D H I$ intron 2 haplotype frequencies among DGA cases and controls

\begin{tabular}{llllll}
\hline & Case (freq) ${ }^{\dagger}$ & Control (freq) ${ }^{\dagger}$ & Fisher's $\boldsymbol{p}$ & Pearson's $\boldsymbol{p}$ & OR (95\%Cl) \\
\hline AAC* & $16.04(0.060)$ & $5.31(0.027)$ & 0.088 & 0.088 & $2.33(0.86-6.34)$ \\
AAG & $17.49(0.065)$ & $5.34(0.027)$ & 0.056 & 0.056 & $2.55(0.95-6.83)$ \\
ATC & $73.09(0.273)$ & $35.43(0.177)$ & 0.015 & 0.015 & $1.74(1.11-2.74)$ \\
ATG & $45.38(0.169)$ & $29.91(0.150)$ & 0.565 & 0.565 & $1.16(0.70-1.92)$ \\
GAC & $21.73(0.081)$ & $24.18(0.121)$ & 0.152 & 0.152 & $0.64(0.35-1.18)$ \\
GAG & $17.75(0.066)$ & $22.17(0.111)$ & 0.087 & 0.087 & $0.57(0.30-1.09)$ \\
GTC & $39.15(0.146)$ & $53.07(0.265)$ & 0.001 & 0.001 & $0.47(0.30-0.75)$ \\
GTG & $37.37(0.139)$ & $24.85(0.123)$ & 0.602 & 0.602 & $1.16(0.67-1.99)$ \\
\hline
\end{tabular}

*Haplotype order: $163+37235 \mathrm{G}>\mathrm{A}, 163+37276 \mathrm{~T}>\mathrm{A}, 163+49526 \mathrm{C}>\mathrm{G}$. The two 5 '-variants were not included, as they did not further split up the haplotypes.

tNumbers refer to reconstructed haplotype numbers among cases (257) and controls (I92), with each individual carrying two chromosomes.

Relative frequencies are given in percent. Not all genotype data was included into analysis, as low frequency haplotypes were dropped.

disequilibrium analysis indicated largely absent LD between the investigated variants $\left(\mathrm{r}^{2}<0.03\right.$; Table 5$)$, suggesting that the CDH1 $163+37235 \mathrm{G}>\mathrm{A}$ SNP may confer an increased susceptibility towards DGC independently of the other variants investigated.

Eighteen of the healthy controls related to the DGC patients were children. A few of them may develop DGC later in their life. We therefore repeated the analysis excluding all 18 children from the controls. The associations between the 163+37235A-containing genotypes/ haplotypes with disease were similar to those obtained without exclusion. As expected, however, all associations were more significant and corresponding risk estimates increased (data not shown).

\section{Discussion}

Inherited genetic risk is believed to be a crucial factor contributing to the incidence of sporadic DGC. Little is known, however, about susceptibility loci that may confer DGC risk without evoking an apparent family history. $\mathrm{CDH1}$, coding for the epithelial adhesion molecule E-cadherin, is one of the few known genes to have an etiologic role in DGC. So far, only one polymorphism located within the $C D H 1$ promoter has been implicated in the sporadic DGC risk of certain populations [10-13]. In this study, we sought to assess a possible contribution of $\mathrm{CDH} 1$ intron 2 variants to disease risk, as this region has recently been shown to be essential for normal $C D H 1$ transcription during adult life, similar to the $\mathrm{CDH} 1$ promoter.

Our present results suggest a role of $\mathrm{CDH} 1$ intron 2 alleles in the risk of developing sporadic DGC and identify the $163+37235 \mathrm{G}>\mathrm{A}$ SNP as a putative susceptibility variant. Both individual genotype data and corresponding haplotype data are consistent with a contribution of the CDH1 $163+37235 \mathrm{~A}$-allele to DGC risk that is independent of the other four investigated $\mathrm{CDH} 1$ intron 2 variants.
A strength of our study is the inclusion of healthy relatives into the control group. Unaffected relatives are expected to share more genetic variants with their related patients compared to unrelated, matched controls, resulting in a reduction of background genetic noise. While the genetic relation may decrease the significance level of an association, the detected genetic differences are likely more robust. Consistent with this, exclusion of relatives too young to have disease strengthened the association of the $163+37235 \mathrm{~A}$-allele with DGC. For all controls, the ratio of the relative frequencies of the A- and G-alleles (A:G) was 0.613 , which is higher than reported for other Caucasian populations (0.38, GenomeBrowser [16]). However, the A:G ratio for unrelated controls only was 0.215 , suggesting that the higher ratio is due to an enrichment of the disease allele among the relatives of DGC patients as one would expect for a high risk population. Somewhat unusual was the lack of any significant LD among the SNPs investigated. Intermarker values between the $163+37235 \mathrm{G}>\mathrm{A}$ and $163+37276 \mathrm{~T}>\mathrm{A}$ variants were available for other populations on the HapMap Browser [21]. Strong LD was also absent in four different ethnic groups $\left(\mathrm{r}^{2}\right.$ range $\left.=0.12-0.52\right)$, suggesting independent segregation of these variants may be common. Together, the data are consistent with a direct association of the $163+37235 \mathrm{~A}$-allele with an increased susceptibility to DGC.

A limitation of this study is its small sample size. The study was designed to detect at the $5 \%$ level of significance an OR of 2.0 for relatively common variants with power $>90 \%$. Thus, the observed lack of significant associations may well be due to inadequate power to detect variants of weaker effect, particularly with rarer alleles. Larger sample sizes will be required to conclusively assess the impact of these variants on disease risk. However, our aim was to identify common susceptibility loci that confer a relatively strong risk and hence might contribute to a significant number of apparent sporadic DGC cases. Another poten- 
Table 5: Linkage disequilibrium between $C D H I$ intron 2 polymorphisms

\begin{tabular}{|c|c|c|c|c|}
\hline \multicolumn{5}{|c|}{$r^{2}$ linkage disequilibrium } \\
\hline & $|63+| 4384 C>T$ & $163+37235 G>A$ & $163+37276 \mathrm{~T}>\mathrm{A}$ & $163+49526 C>G$ \\
\hline $163+14 \mid 84 \Delta$ AGGG & 0.001 & 0.000 & 0.001 & 0.001 \\
\hline$|63+| 4384 C>T$ & - & 0.002 & 0.000 & 0.000 \\
\hline $163+37235 G>A$ & - & - & 0.028 & 0.000 \\
\hline $163+37276 T>A$ & - & - & - & 0.003 \\
\hline
\end{tabular}

tial limiting factor is that the observed association is due to LD with other disease variants not investigated here. A candidate variant may be the CDH1 -160A-allele. Genotype data for the -160 SNP were available for a subgroup of the cases studied. Preliminary analysis suggested absence of LD between the $163+37235$ and the -160 SNP $\left(\mathrm{r}^{2}=0.008 ; \mathrm{BH}\right.$, unpublished results), consistent with an independent contribution of the intron 2 variant to disease. This idea is supported by the consistent association of $163+37235 \mathrm{~A}$-containing haplotypes with DGC (Table $4)$. Additionally, the observation that in mice the promoter and intron 2 are both independently required for CDH1 activity [14] is further evidence for an autonomous role of the intron 2 variant in DGC susceptibility. Moreover, the risk associated with the intron 2 variant remained significant following the adjustment for potential confounding factors, in support of a direct association. An exception was smoking, which reduced the associated risk to borderline significance. Of note, the risk estimates increased in both non-smokers and $H$. pylori-negative patients. While these trends may be due to the relatively low numbers of subjects in stratified subgroups, they may be consistent with genetic DGC risk factors being more important in individuals not exposed to environmental risks.

CDH1 intron 2 sequences are vital both to initiate transcriptional activity and to maintain E-cadherin expression in differentiated epithelia of mice [14]. Given the conserved function of E-cadherin in different species, it is very probable that intron 2 is also essential for CDH1 activity in human epithelia. This is supported by the presence of highly conserved regions within intron 2, suggesting that the conserved elements may be binding sites for transcription factors participating in $C D H 1$ regulation. A search for putative binding sites revealed that the CDH1 163+37235 position lies within a recognition motif of the human nuclear factor I/X (NFIX, OMIM \#164005). According to the TESS web page [17], the $163+37235 \underline{G}$ position (TGGCA) is the most conserved nucleotide within the NFIX recognition sequence, suggesting the $163+37235 \mathrm{~A}-$ allele may alter the affinity of this transcription factor to the cis-regulatory element. Whether NFIX indeed is able to regulate E-cadherin expression in gastric tissue remains to be determined. In mice, however, NFIX is essential for embryonic development [22] and is expressed in many adult tissues including epithelial ones [23]. Genes regulated by NFIX have been identified and include repression of pro-angiogenic PDGFA [24] and p21, where repression surprisingly leads to growth inhibition [25]. NFIX may also slow down cell growth via downregulation of the adenine nucleotide translocase-2 gene (ANT2) [26]. In addition, NFIX has been shown to confer resistance towards transformation by nuclear but not cytoplasmic oncogenes [27]. The reported findings are compatible with a tumour suppressing role of NFIX, where reduced binding of this transcription factor to its recognition sequence may favour tumorigenic events. It is thus of some interest that the chromosomal region 19p13.3, the location of NFIX, appears frequently deleted in some $[28,29]$, however not all [30] series of gastric cancers.

To our knowledge, this is the first study to report an association between an intronic CDH1 variant and sporadic cancer. Similar studies will be required to confirm an association with DGC in other populations/ethnicities and, using a larger sample size, to determine whether the $163+37235$ A variant may also be a disease allele in cohorts from low DGC risk regions. Furthermore, casecontrol studies on other carcinoma types, including other gastric cancer histotypes, should address whether the intron 2 variant is specifically associated with DGC. Regarding the CDH1 promoter SNPs, the -160A-allele has not only been implicated in DGC in Italians [10,11], but also in a Mexican [12] and a Japanese [13] population (here included in disease haplotypes). Not all reports have found significant associations, suggesting population-specific effects or differences in study design [31,32]. To address this heterogeneity, Wang et al. have evaluated data from 11 case-control series and concluded that the $160 \mathrm{~A}$-allele is a gastric cancer susceptibility allele in European, but not Asian populations [33]. However, their meta-analysis did not include very recent studies reporting positive associations [11-13] and therefore may underestimate the contribution of the -160A-allele to gastric cancer. Further positive associations have been observed with sporadic carcinomas at other sites such as prostate [34,35], urether [36], bladder [37], breast [38], 
colorectum, and endometrium [11]. Another $C D H 1$ promoter variant, -347insA, has not been associated with sporadic DGC so far, but appears to increase susceptibility to colorectal cancer [39] and to contribute to oesophageal/cardiac cancer risk [40]. Such observations imply that functional $C D H 1$ variants may be involved in the susceptibility towards a broad range of epithelial cancers, consistent with the expression pattern of E-cadherin in tissues. It appears likely that, in many instances, $\mathrm{CDH} 1$ variants will require the presence of other etiologic factors to increase disease risk, as E-cadherin deficiency is usually associated with cancer progression rather than initiation [41]. Furthermore, $\mathrm{CDH1}$ polymorphisms might also affect the differentiation degree of tumours; preliminary results from our laboratory suggest an overrepresentation of specific $C D H 1$ haplotypes in poorly differentiated lung carcinomas (Emily Wilson, HSc-thesis). Therefore, the role of the intronic $C D H 1 \quad 163+37235 \mathrm{~A}$ variant as a disease allele may not be limited to sporadic DGC risk.

\section{Conclusion}

We report the identification of a new putative susceptibility variant for DGC located within conserved sequences of CDH1 regulatory intron 2. Both individual genotype and haplotype data suggest a contribution of the CDH1 $163+37235 \mathrm{~A}$-allele to sporadic DGC risk that is independent of other $C D H 1$ variants within conserved intron 2 regions. A larger confirmatory study involving other populations and including complete $\mathrm{CDH} 1$ haplotypes will be required to assess the population-specificity and the relative contribution of the $163+37235 \mathrm{~A}$-allele to disease. The establishment of heritable DGC risk factors will be helpful particularly with respect to the difficult and often delayed diagnosis of diffuse-type stomach cancer. Given the universal expression of E-cadherin in epithelial tissues, this exploratory study may also provide a basis to investigate the role of the $C D H 1163+37235 \mathrm{G}>\mathrm{A}$ SNP in the incidence and progression of tumours other than DGC.

\section{Competing interests}

The authors declare that they have no competing interests.

\section{Authors' contributions}

SN performed the SSCP screen, the genotyping, analysed the data, and helped to draft the manuscript. HM identified the conserved sequences, designed the PCR primers, the PCR reactions and the genotyping assays. FG organised the sample collection and patient data, participated in the collection of blood, performed case/control interviews and helped to design the study. AR participated in the sample collection and isolated the DNA. EW participated in the genotyping and in the data analysis. AD helped to analyse the data and to design the study. CM helped to analyse the data. TM helped to analyse the data and to draft the manuscript. PG helped to design the study and revised the manuscript. MM helped to organise samples and to design the study. BH conceived of the study, helped to analyse the data and drafted the manuscript. All authors read and approved the final manuscript.

\section{Acknowledgements}

This study was supported by the Health Research Council of New Zealand. We wish to thank all volunteers for their participation in this study.

\section{References}

I. Ushijima T, Sasako M: Focus on gastric cancer. Cancer Cell 2004, 5: $12 \mid-125$.

2. Lauren PA, Nevalainen TJ: Epidemiology of intestinal and diffuse types of gastric carcinoma. A time-trend study in Finland with comparison between studies from high- and low-risk areas. Cancer 1993, 71:2926-2933.

3. Humar B, Fukuzawa R, Blair V, Dunbier A, More H, Charlton A, Yang HK, Kim WH, Reeve AE, Martin I, Guilford P: Destabilized adhesion in the gastric proliferative zone and c-Src kinase activation mark the development of early diffuse gastric cancer. Cancer Res 2007, 67:2480-2489.

4. Karayiannakis AJ, Syrigos KN, Chatzigianni E, Papanikolaou S, Karatzas G: E-cadherin expression as a differentiation marker in gastric cancer. Hepatogastroenterology 1998, 45:2437-2442.

5. Larue L, Ohsugi M, Hirchenhain J, Kemler R: E-cadherin null mutant embryos fail to form a trophectoderm epithelium. Proc Natl Acad Sci USA 1994, 9 I:8263-8267.

6. Berx G, Becker KF, Hofler H, van Roy F: Mutations of the human E-cadherin (CDHI) gene. Hum Mut 1998, I 2:226-237.

7. Tamura G, Yin J, Wang S, Fleisher AS, Zou T, Abraham JM, Kong D, Smolinski KN, Wilson KT, James SP, Silverberg SG, Nishizuka S, Terashima M, Motoyama T, Meltzer SJ: E-Cadherin gene promoter hypermethylation in primary human gastric carcinomas. J Natl Cancer Inst 2000, 92:569-573.

8. Guilford P, Hopkins J, Harraway J, McLeod M, McLeod N, Harawira $P$, Taite $H$, Scoular R, Miller A, Reeve AE: E-cadherin germline mutations in familial gastric cancer. Nature 1998, 392:402-405.

9. Guilford P, Blair V, More H, Humar B: A short guide to hereditary diffuse gastric cancer. Hered Cancer Clin Pract 2007, 5:183-194 [http://www.termedia.pl/maga zine.php? magazine id $=\mid 4 \&$ year $=2007 \&$ vol ume=4\&magazine subpage=ARCHIVE NUMBER]

10. Humar B, Graziano F, Cascinu S, Catalano V, Ruzzo AM, Magnani M, Toro T, Burchill T, Futschik ME, Merriman T, Guilford P: Association of CDHI haplotypes with susceptibility to sporadic diffuse gastric cancer. Oncogene 2002, $21: 8192-8195$.

II. Cattaneo F, Venesio T, Molatore S, Russo A, Fiocca R, Frattini M, Scovassi Al, Ottini L, Bertario L, Ranzani GN: Functional analysis and case-control study of - $160 \mathrm{C} / \mathrm{A}$ polymorphism in the E-cadherin gene promoter: association with cancer risk. Anticancer research 2006, 26:4627-4632.

12. Medina-Franco H, Ramos-De la Medina A, Vizcaino G, Medina-Franco $\mathrm{JL}$ : Single nucleotide polymorphisms in the promoter region of the E-cadherin gene in gastric cancer: case-control study in a young Mexican population. Ann Surg Oncol 2007, 1 4:2246-2249.

13. Yamada H, Shinmura K, Ikeda S, Tao H, Otani T, Hanaoka T, Tsuneyoshi T, Tsugane S, Sugimura H: Association between CDHI haplotypes and gastric cancer risk in a Japanese population. Scand J Gastroenterol 2007, 42: I479-I 485.

14. Stemmler MP, Hecht A, Kemler R: E-cadherin intron 2 contains cis-regulatory elements essential for gene expression. Development 2005, 132(5):965-976.

15. GeneFisher [http://bibiserv.techfak.uni-bielefeld.de/genefisher2]

16. GenomeBrowser [http://www.ensembl.org/index.html]

17. TESS [http://www.cbil.upenn.edu/cgi-bin/tess/tess]

18. Humar B, Toro T, Graziano F, Muller H, Dobbie Z, Kwang-Yang H, Eng C, Hampel H, Gilbert D, Winship I, Parry S, Ward R, Findlay M, Christian A, Tucker M, Tucker K, Merriman T, Guilford P: Novel germline $\mathrm{CDH}$ I mutations in hereditary diffuse gastric cancer families. Hum Mut 2002, 19:5।8-525.

19. SHEsis [http://analysis.bio-x.cn/myAnalysis.php] 
20. Shi YY, He L: SHEsis, a powerful software platform for analyses of linkage disequilibrium, haplotype construction, and genetic association at polymorphism loci. Cell Res 2005, 15:97-98.

21. HapMap Browser [http://www.hapmap.org]

22. Driller K, Pagenstecher A, Uhl M, Omran H, Berlis A, Grunder A, Sippel AE: Nuclear factor I $\mathbf{X}$ deficiency causes brain malformation and severe skeletal defects. Mol Cell Biol 2007, 27:3855-3867.

23. Chaudhry AZ, Lyons GE, Gronostajski RM: Expression patterns of the four nuclear factor I genes during mouse embryogenesis indicate a potential role in development. Dev Dyn 1997, 208:3। 3-325.

24. Rafty LA, Santiago FS, Khachigian LM: NFI/X represses PDGF Achain transcription by interacting with $\mathrm{Spl}$ and antagonizing Sp I occupancy of the promoter. EMBO J 2002, 21:334-343.

25. Ouellet S, Vigneault F, Lessard M, Leclerc S, Drouin R, Guerin SL: Transcriptional regulation of the cyclin-dependent kinase inhibitor IA (p2I) gene by NFI in proliferating human cells. Nucleic Acids Res 2006, 34:6472-6487.

26. Luciakova K, Barath P, Poliakova D, Persson A, Nelson BD: Repression of the human adenine nucleotide translocase-2 gene in growth-arrested human diploid cells: the role of nuclear factor-I. J Biol Chem 2003, 278:30624-30633.

27. Schuur ER, Kruse U, lacovoni JS, Vogt PK: Nuclear factor I interferes with transformation induced by nuclear oncogenes. Cell Growth Differ 1995, 6:219-227.

28. Furuya $T$, Uchiyama T, Adachi A, Chochi Y, Oga A, Kawauchi S, Ishiglo K, Sasaki K: Relation of DNA ploidy to genetic aberrations detected by chromosomal CGH and FISH in gastric adenocarcinomas. Oncol Rep 2006, 15:|49|-|496.

29. Weiss MM, Kuipers EJ, Postma C, Snijders AM, Pinkel D, Meuwissen SG, Albertson D, Meijer GA: Genomic alterations in primary gastric adenocarcinomas correlate with clinicopathological characteristics and survival. Cell Oncol 2004, 26:307-3I7.

30. Buffart TE, Carvalho B, Hopmans E, Brehm V, Kranenbarg EK, SchaaijVisser TB, Eijk PP, van Grieken NC, Ylstra B, Velde Cl van de, Meijer GA: Gastric cancers in young and elderly patients show different genomic profiles. J Pathol 2007, 2 I I:45-5I.

31. Pharoah PD, Oliveira C, Machado JC, Keller G, Vogelsang H, Laux H, Becker KF, Hahn H, Paproski SM, Brown LA, Caldas C, Huntsman D: $\mathrm{CDHI} \mathrm{c}-160 \mathrm{a}$ promotor polymorphism is not associated with risk of stomach cancer. Int ] Cancer 2002, I01:196-197.

32. Park WS, Cho YG, Park JY, Kim CJ, Lee JH, Kim HS, Lee JW, Song YH, Park CH, Park YK, Kim SY, Nam SW, Lee SH, Yoo NJ, Lee JY: A single nucleotide polymorphism in the E-cadherin gene promoter- 160 is not associated with risk of Korean gastric cancer. J Korean Med Sci 2003, 18:50I-504 [http://jkms.org/contents/ jkms. php? pubyear $=2003 \& \mathrm{vol}=18 \& \mathrm{fpage}=50 \mathrm{I}]$

33. Wang GY, Lu CQ, Zhang RM, Hu XH, Luo ZW: The E-cadherin gene polymorphism 160C->A and cancer risk: A HuGE review and meta-analysis of 26 case-control studies. Am J Epidemiol 2008, 167:7-14.

34. Verhage BA, van Houwelingen K, Ruijter TE, Kiemeney LA, Schalken JA: Single-nucleotide polymorphism in the E-cadherin gene promoter modifies the risk of prostate cancer. Int J Cancer 2002, 100:683-685.

35. Lindstrom S, Wiklund F, Jonsson BA, Adami HO, Balter K, Brookes AJ, Xu J, Zheng SL, Isaacs WB, Adolfsson J, Gronberg H: Comprehensive genetic evaluation of common E-cadherin sequence variants and prostate cancer risk: strong confirmation of functional promoter SNP. Hum Genet 2005, I I 8:339-347.

36. Tsukino $H$, Kuroda $Y, N a k a o ~ H$, Imai $H$, Inatomi $H$, Kohshi $K$, Osada $\mathrm{Y}, \mathrm{Katoh} \mathrm{T}$ : E-cadherin gene polymorphism and risk of urothelial cancer. Cancer Lett 2003, 195:53-58.

37. Zhang X, Ma X, Zhu QG, Li LC, Chen Z, Ye ZQ: Association between a C/A single nucleotide polymorphism of the $E$-cadherin gene promoter and transitional cell carcinoma of the bladder. J Urol 2003, 170:1379-1382.

38. Yu JC, Hsu HM, Chen ST, Hsu GC, Huang CS, Hou MF, Fu YP, Cheng TC, Wu PE, Shen CY: Breast cancer risk associated with genotypic polymorphism of the genes involved in the estrogenreceptor-signaling pathway: a multigenic study on cancer susceptibility. J Biomed Sci 2006, 13:419-432.

39. Shin Y, Kim IJ, Kang HC, Park JH, Park HW, Jang SG, Lee MR, Jeong SY, Chang HJ, Ku JL, Park JG: A functional polymorphism (-347
G--> GA) in the E-cadherin gene is associated with colorectal cancer. Carcinogenesis 2004, 25:2173-2176.

40. Zhang XF, Wang YM, Wang R, Wei LZ, Li Y, Guo W, Wang N, Zhang $\mathrm{JH}$ : [Correlation of E-cadherin polymorphisms to esophageal squamous cell carcinoma and gastric cardiac adenocarcinoma]. Ai Zheng 2005, 24:5/3-519 [http://www.cjcsysu.cn/fulltext new.asp? $y=2005 \& m=5 \& y m=5 \mid 3]$. [Article in Chinese]

41. Cavallaro U, Christofori G: Cell adhesion and signalling by cadherins and Ig-CAMs in cancer. Nat Rev Cancer 2004, 4(2): $1 \mid 8-132$.

\section{Pre-publication history}

The pre-publication history for this paper can be accessed here:

http://www.biomedcentral.com/1471-2407/8/138/pre pub
Publish with Bio Med Central and every scientist can read your work free of charge

"BioMed Central will be the most significant development for disseminating the results of biomedical research in our lifetime. "

Sir Paul Nurse, Cancer Research UK

Your research papers will be:

- available free of charge to the entire biomedical community

- peer reviewed and published immediately upon acceptance

- cited in PubMed and archived on PubMed Central

- yours - you keep the copyright 